Supporting Information

\title{
A High-Throughput Two-Dimensional Polymerase Chain Reaction Technology
}

Yuxia Zhan ${ }^{1,2}$, Jun Zhang ${ }^{1,2}$, Shuang Yao ${ }^{1,2}$ \& Guanghua Luo ${ }^{1,2 *}$

${ }^{1}$ Comprehensive Laboratory, the Third Affiliated Hospital of Soochow University, Changzhou 213003, Jiangsu Province, China.

${ }^{2}$ Changzhou Key Lab of Individualized Diagnosis and Treatment Associated with High

Technology Research, Changzhou 213003, Jiangsu Province, China

* Corresponding to Guanghua Luo: shineroar@163.com

\section{Supporting Information List}

1. Supporting notes

2. Table S1. Pre-tags and detecting probe sequences.

3. Table S2. Selected pre-tag sequences used for the synthesis of the 2D PCR primers.

4. Figure S1. Melting curves of the $H B B \& H B D$ detected in both the Cy5 and FAM channels.

5. Figure S2. Two-dimensional method of identifying different HPV types and HBB\&HBD

6. Figure S3. The influence of $\mathrm{Mg}^{2+}$ on the melting temperature.

7. Figure S4. Optimal concentration of the probe exploring experiment.

8. Figure S5. Untagged primer optimal concentration exploration.

9. Figure S6. Change in the melting curve of the same HPV 45 sample with an increase in the HPV 68 plasmid concentration. 


\section{Supporting notes}

Tag and probe design principle. The tag sequence design is a critical part of designing suitable primers and probes. Generating the 2D PCR primers and their matching probes is likely to require a few steps. First, we need to select gene-specific primers that will be added into one multiplex PCR system but will not cause unspecific reactions. By using standard nucleotide BLAST at NCBI (http://www.ncbi.nlm.nih.gov), or some software for primer design, the possibility of causing unspecific reactions, such as primer dimers, which affect the accuracy of multiplex PCR, can be preliminarily ruled out. In the second step, tags and probes are designed. The first tag sequence is designed randomly. By utilizing the website and software mentioned above, we can ensure that this first tag sequence will not trigger nonspecific reactions. For a more rapid design, the original sequence may be directly used as a base-quenching probe sequence, which can be a fluorophore labeled at the 3' or 5' end. If the fluorophore is at the 5' end, the $3^{\prime}$ end will need to be inactivated by modifying with groups such as phosphate groups. However, if labeled on the 3' end, the 5' end will not need any modification. In the third step, different sites and numbers of base mutations are made on the primarily designed tag to create various homologous sequences. Then, we can embark on screening for homologous tags that have distinguishable Tm values. DNA segments containing the reverse complement sequences of these tags are synthesized for the Tm value assessment. We named these pre-tags for easier demonstration. Normally, a difference of $0.8-1^{\circ} \mathrm{C}$ between the $\mathrm{Tm}$ values is sufficient to separate two melting curves during the melting curve analysis. All the different probes and matching tags of 2D PCR are designed in this way.

When the primers and probes were designed for the target genes, we identified some tips to more quickly design suitable tags. These tips are useful for predicting the change in the melting temperature of the original strand, according to the sites and types of the mutated bases. We found that base $G$ mutations might cause a $6-8^{\circ} \mathrm{C}$ decrease in the Tm value, while $\mathrm{A}$ or $\mathrm{C}$ mutations would cause a $4-6^{\circ} \mathrm{C}$ decrease, and $\mathrm{T}$ mutations would cause a $2-4^{\circ} \mathrm{C}$ decrease. Inappropriate numbers of $\mathrm{G}$ mutations and/or inappropriate mutation sites, such as three adjacent G mutations, might affect the effective hybridization of the probe with the reverse complement sequences of the tags. Not all the best melting curves came from the tags with identical probe sequences. In the 3-channel detection system, the melting peaks of $H B B \& H B D$ in most samples were not particularly intense. This is because the relatively high temperature has a negative effect on the Cy5 dye and weakens its fluorescence intensity ${ }^{14}$. Hence, attention must be paid to the effect of the temperature on the fluorescence of the dyes and the characteristics of the different types of fluorophores to obtain better results.

Tag design of the $9 \mathrm{HPV}$ types and $H B B \& H B D$. After ensuring that no unspecific reactions occurred by using the BLAST tool at NCBI, the first tag sequence was designed. From the 5' end to the 3' end, the sequence was CCATTACAACCCTTATACTACTCCAC. To generate the first probe, we initially decided to label the fluorophore at the 3' end. We also labeled the fluorophore at the 5' end and used phosphate to modify the 3' end.

For the pre-tag Tm exploration, a 5-G base cluster was added to the complete reverse complement sequence of the first tag sequence to enhance the quenching effect (Table S1) ${ }^{13}$; this is how pre-tag F10 was generated. Then, we randomly chose different sites and numbers of bases to mutate, which produced a further 9 pre-tags, F1 to F9. From the results of the Tm exploration, we concluded several 
points about predicting the change in the Tm values according to the type and number of mutated bases, which can save time. Subsequently, H17 was designed. With the assistance of these points and some creative mutation protocols, pre-tags $\mathrm{H} 1$ to $\mathrm{H} 19$ were made. Table S1 also demonstrates the approximate Tm values of most of the pre-tags, apart from the exact sequences. However, these Tm values were acquired during the initial tests and are therefore only for reference. When we used the hot start PCR system, we explored the optimal $\mathrm{Mg}^{2+}$ concentration, and the result indicated that the Tm could be affected by the $\mathrm{Mg}^{2+}$ concentration (Figure S3). It is obvious that some of the pre-tags have $\mathrm{Tm}$ values that are close to each other (Table S1). These homologous sequences actually provide us with more options when choosing a tag for one target gene.

Since there was only one gene that would be detected in the Cy5 channel, the pre-tag selection step was skipped, and the sequence CTCTATGTCACTTCCCCTTGGTTCTCTCATC (5' to 3') was directly used as the $H B B \& H B D$ primer tag for the Cy5 channel. The 3' end fluorophore-labeled probes worked the same way as the $5^{\prime}$ end labeled probe. However, to shorten the length of the primers, we decided to use the $5^{\prime}$ end labeled probes, which did not necessarily require extra $G$ bases to achieve a better quenching effect ${ }^{13}$. After careful selection, except the tag in Cy5 channel, another 10 pre-tags were selected (Table S2), and the extra G bases were removed when using them as tags. In the pre-tags whose numbers start with $\mathrm{H}$, the last base $\mathrm{T}$ at the 3 ' end was excluded to achieve a better quenching effect when transforming the pre-tags into tags.

General PCR systems and programs. The PCR system used for the exploration of the Tm values of the pre-tags was composed of $2.5 \mu \mathrm{L}$ of $10 \times$ buffer without $\mathrm{Mg}^{2+}$ (Biocolor Technology, China), $1.5 \mu \mathrm{L}$ of $25 \mathrm{mM} \mathrm{MgCl}_{2}$ (Biocolor Technology, China), $0.5 \mu \mathrm{L}$ of $4 \times 10 \mathrm{mM}$ dNTPs (Biocolor Technology, China), $0.25 \mu \mathrm{L}$ of $5 \mathrm{U} / \mu \mathrm{L}$ Taq polymerase (Biocolor Technology, China), $0.1 \mu \mathrm{L}$ of $10 \mu \mathrm{M}$ pre-tag, $0.1 \mu \mathrm{L}$ of 10 $\mu \mathrm{M}$ probe, and $20.05 \mu \mathrm{L}$ of deionized water. The program was as follows: $95^{\circ} \mathrm{C}$ for $10 \mathrm{~s}$ and $30^{\circ} \mathrm{C}$ for 4 min, in which the temperature continuously increased to $80^{\circ} \mathrm{C}$ during fluorescence acquisition.

The PCR system used for the quantification of HPV 18 (forward primer: GACAGCACAGGCATTGTTCCAT, reverse primer: CTCCAGCCGCTCCCCTAAT, probe: FAM-TTTGCAGGAGGCAGCACAGAAAACAGT-BHQ1 ), HPV 45 (forward primer: TAAAAAGTAACTGCCAAGCCAAAT, reverse primer: CTCCAATCCCCACCTTCATCT, probe: FAM-AGAGCACAAAAACGCCAAATGAATATGTCTC-BHQ1), HPV 68 (forward primer: TAGCCATGYTAGATGACGCAAC, reverse primer: GGTGTCTGTGTTTTCTRTCTAAACTTATTG, probe: FAM-ATGAGAAATGCATTAGATGGTAAC-BHQ1) was composed of $2.5 \mu \mathrm{L}$ of $10 \times$ buffer without $\mathrm{Mg}^{2+}$ (Biocolor Technology, China), $1.5 \mu \mathrm{L}$ of $25 \mathrm{mM} \mathrm{MgCl}_{2}$ (Biocolor Technology, China), $0.5 \mu \mathrm{L}$ of $4 \times 10 \mathrm{mM}$ dNTPs (Biocolor Technology, China), $0.25 \mu \mathrm{L}$ of $5 \mathrm{U} / \mu \mathrm{L}$ Taq polymerase (Biocolor Technology, China), $0.4 \mu \mathrm{L}$ of $10 \mu \mathrm{M}$ forward primer, $0.4 \mu \mathrm{L}$ of $10 \mu \mathrm{M}$ reverse primer, $0.4 \mu \mathrm{L}$ of $10 \mu \mathrm{M}$ probe, and $2 \mu \mathrm{L}$ of the samples, and then, we added deionized water to reach a total volume of $25 \mu \mathrm{L}$. The program was as follows: $95^{\circ} \mathrm{C}$ for $2 \mathrm{~min}, 95^{\circ} \mathrm{C}$ for $10 \mathrm{~s}$ and $60^{\circ} \mathrm{C}$ for $30 \mathrm{~s}$ for 40 cycles, and $40^{\circ} \mathrm{C}$ for $30 \mathrm{~s}$.

The final version of the optimized 2D multiplex PCR system comprised $2.5 \mu \mathrm{L}$ of $10 \times$ Immobuffer, $1 \mu \mathrm{L}$ of $50 \mathrm{mM} \mathrm{MgCl}, 0.7 \mu \mathrm{L}$ of $2.5 \mathrm{mM}$ dNTPs, $0.5 \mu \mathrm{L}$ of $5 \mathrm{U} / \mu \mathrm{L}$ IMMOLASE DNA polymerase, $0.4 \mu \mathrm{L}$ of each $10 \mu \mathrm{M}$ probe, $0.1 \mu \mathrm{L}$ of each $10 \mu \mathrm{M}$ primer with a tag $(0.2 \mu \mathrm{L}$ for HPV 16$), 0.6 \mu \mathrm{L}$ of $10 \mu \mathrm{M}$ primer without a tag, deionized water to reach a total volume of $23 \mu \mathrm{L}$ and, finally, $2 \mu \mathrm{L}$ of the sample.

The PCR programs used for the hot-start reaction system were the same: the hot start process used to activate the DNA polymerase involved heating at $95^{\circ} \mathrm{C}$ for $10 \mathrm{~min}$; the amplification process was started immediately after the DNA polymerase was hot-activated and consisted of 40 heating cycles at 
$95^{\circ} \mathrm{C}$ for $10 \mathrm{~s}$ and $60^{\circ} \mathrm{C}$ for $30 \mathrm{~s}$; the fluorescence acquisition was commenced by heating at $30^{\circ} \mathrm{C}$ for 4 min, the temperature was gradually increased from $30^{\circ} \mathrm{C}$ to $80^{\circ} \mathrm{C}$ with a ramp rate of $0.1{ }^{\circ} \mathrm{C} / \mathrm{s}$, and the fluorescence signal was acquired continuously; the final step was cooling at $40^{\circ} \mathrm{C}$ for $30 \mathrm{~s}$.

The PCR programs used for the SILGOLBIO 14+2 HPV detection qPCR kit involved heating at $25^{\circ} \mathrm{C}$ for $10 \mathrm{~min}$ and $95^{\circ} \mathrm{C}$ for $10 \mathrm{~min}$, and 40 cycles were performed by heating at $95^{\circ} \mathrm{C}$ for $15 \mathrm{~s}$ and $60^{\circ} \mathrm{C}$ for 30 $\mathrm{s}$; finally, the fluorescence signal was acquired by heating at $40^{\circ} \mathrm{C}$ for $30 \mathrm{~s}$.

Optimization of the 2D PCR system for ten-gene detection. Efforts were devoted to optimizing the reaction system by tuning parameters such as the $\mathrm{Mg}^{2+}$ concentration (Figure S3), probe concentration (Figure S4) and untagged primer concentration (Figure S5). The aim of the optimal probe concentration experiment was to ensure that there were sufficient probes to interact with the target sequences in order to enhance the fluorescence signal. We also needed to avoid the interference of the high fluorescence background. We designed 5 PCR systems for the FAM channel, all of which only contained the probe and primers used in this channel. The 5 reaction systems were termed (a), (b), (c), (d) and (e). System (a) contained $0.1 \mu \mathrm{L}$ of the probes in a $25 \mu \mathrm{L}$ reaction system, while (b), (c), (d) and (e) contained $0.2 \mu \mathrm{L}, 0.3 \mu \mathrm{L}, 0.4 \mu \mathrm{L}$ and $0.5 \mu \mathrm{L}$ of the probes, respectively. Three samples were employed. Sample one was the HPV 18 plasmids with a concentration of $\sim 10^{4}$ copies/ $\mu \mathrm{L}$. Sample two was human genomic DNA extracted from whole blood. Sample three was an isotropic mix of samples one and two. Each sample was detected in these five reaction systems. The results revealed that the best volume for the $10 \mu \mathrm{M}$ probe was $0.4 \mu \mathrm{L}$ in a $25 \mu \mathrm{L}$ reaction system (Figure S4).

To address the competition that occurred for the tag reverse complement sequences between the probes and tags, we adjusted the volume of the primers. In the $25 \mu \mathrm{L}$ single tube reaction system, we designed 4 reaction systems with 4 different volumes of untagged primers $(0.2,0.4,0.6$ and $0.8 \mu \mathrm{L})$, while the primer with the tag remained at $0.1 \mu \mathrm{L}$ in $25 \mu \mathrm{L}$. The preliminary reaction system in which the tagged and untagged primer volumes were all at $0.1 \mu \mathrm{L}$ was not repeated in this test, because previous tests showed that this reaction system was unable to produce melting curves for a few HPV plasmids. We used the human genomic DNA samples extracted from human whole blood and twice diluted these samples by ten times. Thus, we obtained three samples with different concentrations. We compared the results of the lowest, medium and highest concentrations of the samples and found that the best volume of the untagged primers was $0.6 \mu \mathrm{L}$ in the $25 \mu \mathrm{L}$ PCR system (Figure S5). We also used this new system to test each type of HPV plasmid to ensure that this adjustment worked. 
Table S1. Pre-tags and detecting probe sequences.

\begin{tabular}{|c|c|c|c|}
\hline Pre-tag & Pre-tag sequence $\left(5^{\prime} \rightarrow 3^{\prime}\right)$ & $\begin{array}{ll}\text { Approximate } & \mathrm{Tm} \\
\text { value }\left({ }^{\circ} \mathrm{C}\right) & \\
\end{array}$ & Detecting probe sequence $\left(5^{\prime} \rightarrow 3^{\prime}\right)$ \\
\hline F1 & GGGGGGTGGAGTAATATAACGGTAGTAATGG & 37.5 & \multirow{10}{*}{ ССАТTACAACCСТTAТАСТАСТССАС } \\
\hline F2 & GGGGGGTGGAGTAGCTTAAGGGTTCTAATGG & 44 & \\
\hline F3 & GGGGGGTGGAGTAGTATAAGGCAAGTAATGG & 49 & \\
\hline F4 & GGGGGGTGGAGTACATTAAGGGTTGTAATGG & 50 & \\
\hline F5 & GGGGGGTGGAGTAGTATAAGGGCAGTAATGG & 53 & \\
\hline F6 & GGGGGGTGGAGTAGTATAAGGGTAGTAATGG & 54 & \\
\hline F7 & GGGGGGTGGAGTAGTATAAAGGTTGTAATGG & 54 & \\
\hline F8 & GGGGGGTGGAGTAATATAAGGGTTGTAATGG & 54 & \\
\hline F9 & GGGGGGTGGAGTAGTATAAGGGTTGTATTGG & 56.5 & \\
\hline F10 & GGGGGGTGGAGTAGTATAAGGGTTGTAATGG & 62.5 & \\
\hline H1 & GGGGGGTGAAAGGCCTGGAAGTTGAAAGATAGGT & 38.5 & \multirow{19}{*}{ АССТАТСТСТСААССТССАССССТTТСАС } \\
\hline $\mathrm{H} 2$ & GGGGGGTGAAAGGGGTGATTAAAATTATTATAAT & 39.5 & \\
\hline H3 & GGGGGGTGAAAGTGGTGGCGATTGAGACATAGGT & 41 & \\
\hline $\mathrm{H} 4$ & GGGGGGTGAAACGGGTGGTGGTTAAGAGATATGT & 43.5 & \\
\hline H5 & GGGGGGTGAAAGTAGTGGAGGTTGAAAGACAGGT & 45 & \\
\hline H6 & GGGGGGTGAAAGACGTGGAGGTTATGAGATAGGT & 47.5 & \\
\hline H7 & GGGGGGTGAAACGGGTGGAGGTTAAGAGATATGT & 48.5 & \\
\hline H8 & GGGGGGTGAAAGCAGTGGAGGTTAAGAGATAGGT & 50 & \\
\hline H9 & GGGGGGTGAAAGGGGTGGAGGTTCCTAGATAGGT & 55 & \\
\hline H10 & GGGGGGTGAAAGGAGTGGAGGCTGAGAGATAGGT & 56 & \\
\hline H11 & GGGGGGTGAAAGGGGTGGAACTTGAGAGATAGGT & 56 & \\
\hline H12 & GGGGGGTGAAAGGGGCGGAGGTTGAGAGTAAGGT & 58.5 & \\
\hline H13 & GGGGGGTGAAAGGGGTGGAGGTTACGAGATAGGT & 60 & \\
\hline H14 & GGGGGGTGAAAGGGGTGAAGGTTGAGAGATAGGT & 62 & \\
\hline H15 & GGGGGGTGAAAGGGGTGGAGGTTGAGAAATAGGT & 62 & \\
\hline H16 & GGGGGGTGAAAGGGGTGGAGGTTGAGAGTAAGGT & 64 & \\
\hline H17 & GGGGGGTGAAAGGGGTGGAGGTTGAGAGATAGGT & 68 & \\
\hline H18 & GGGGGGTCAAAGGGGTGGAGGTTGAGAGATAGAT & Abnormal curves & \\
\hline H19 & GGGGGGTGAAAGAAATGGAGGTTGAGAGATAGGT & Abnormal curves & \\
\hline
\end{tabular}

The sequences of all the pre-tags and probes, and the approximate Tm values of each pre-tag. In this table, we demonstrated the precise sequences that we designed for the three sets of pre-tags. Some of the pre-tags could not interact with the probe, which probably occurred because of the inappropriate base mutation, and the bolded letters are the bases mutated from the one designed firstly of each set. 
Table S2. Selected pre-tag sequences used for the synthesis of the 2D PCR primers.

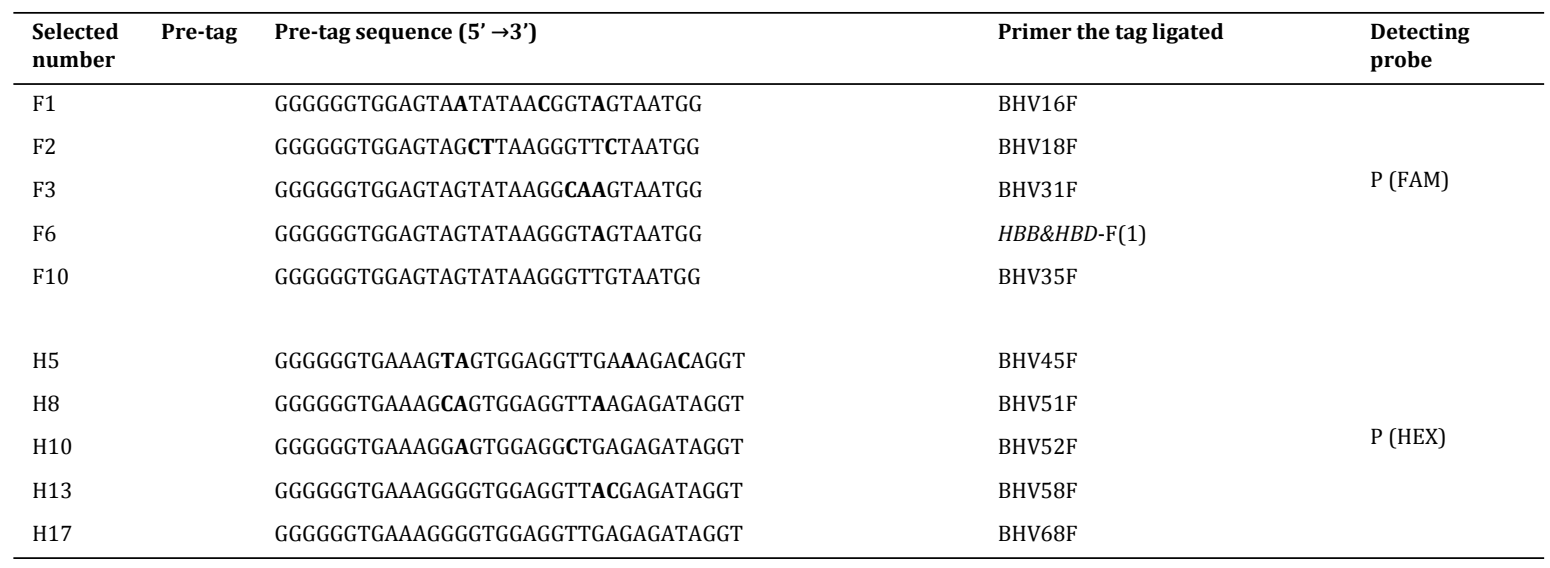

Among the pre-tags we designed, the sequences demonstrated in this table were sequences chosen to make the tags. Nos. F10 and H17 contained the completely reversed complement sequences of the probes with the same extra bases, and the bolded letters in the sequences were the bases mutated from the bases of the complement sequences. We also showed the primer names whose tags comprised these pre-tags in the end.

\section{A $H B B \& H B D$ in the Cy5 channel B $H B B \& H B D$ in the FAM channel}

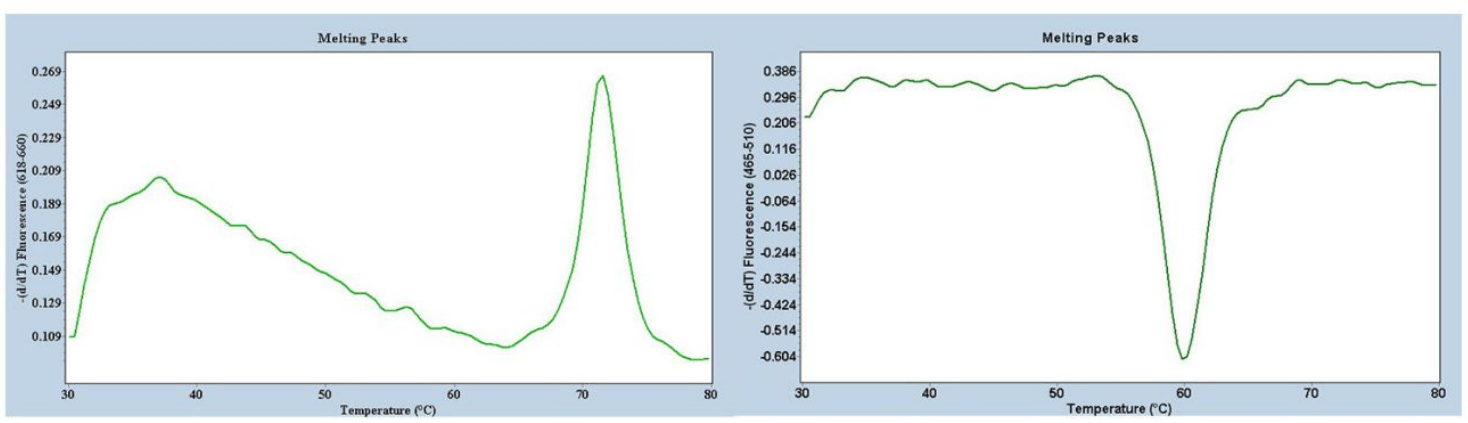

Figure S1. Melting curves of the $H B B \& H B D$ detected in both the Cy5 and FAM channels. (A) The melting temperature of the $H B B \& H B D$ in the Cy5 channel was approximately $72^{\circ} \mathrm{C}$. Due to the particular nature of the Cy5 dye, the melting curve was a melting peak instead of a valley. (B) The HBB\&HBD was detected in the FAM channel with a Tm value of approximately $60^{\circ} \mathrm{C}$. 


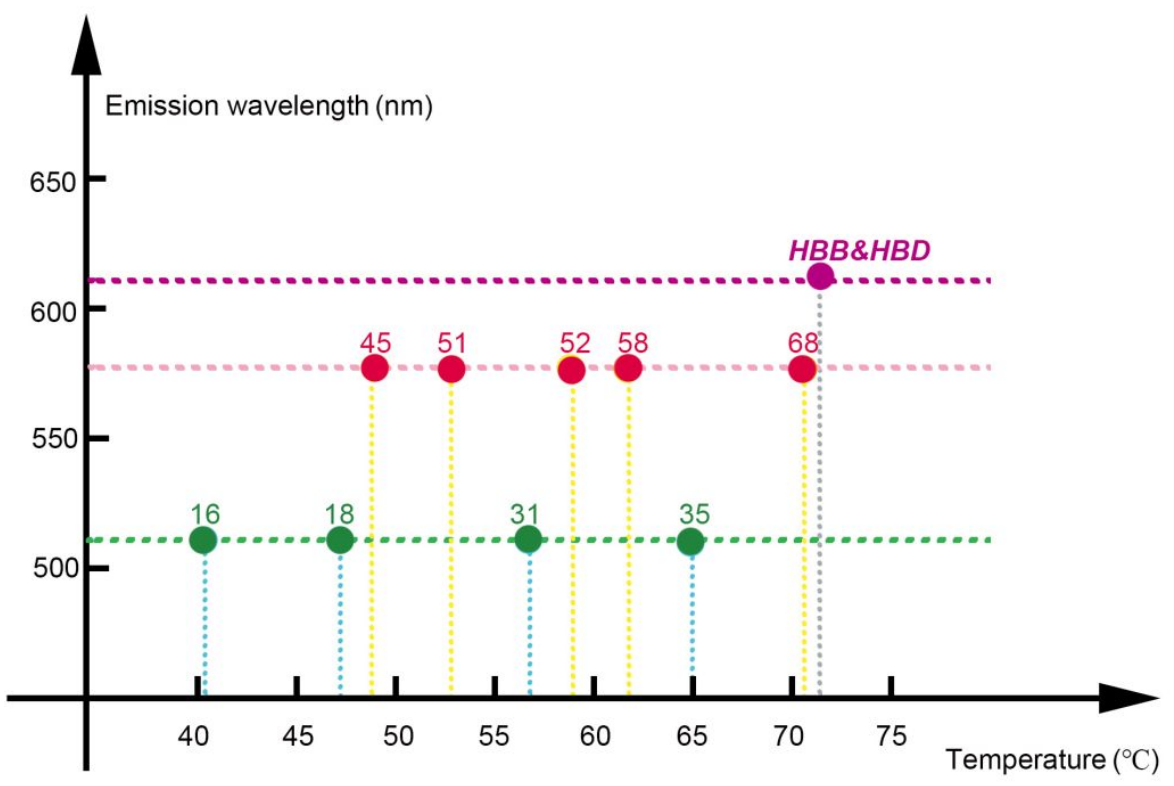

Figure S2. Two-dimensional method of identifying different HPV types and $H B B \& H B D$. We use a coordinate system to simulate the distinctive product identification using 2D multiplex PCR in the feasibility test. Each gene is identified by both the detection channel and Tm value.

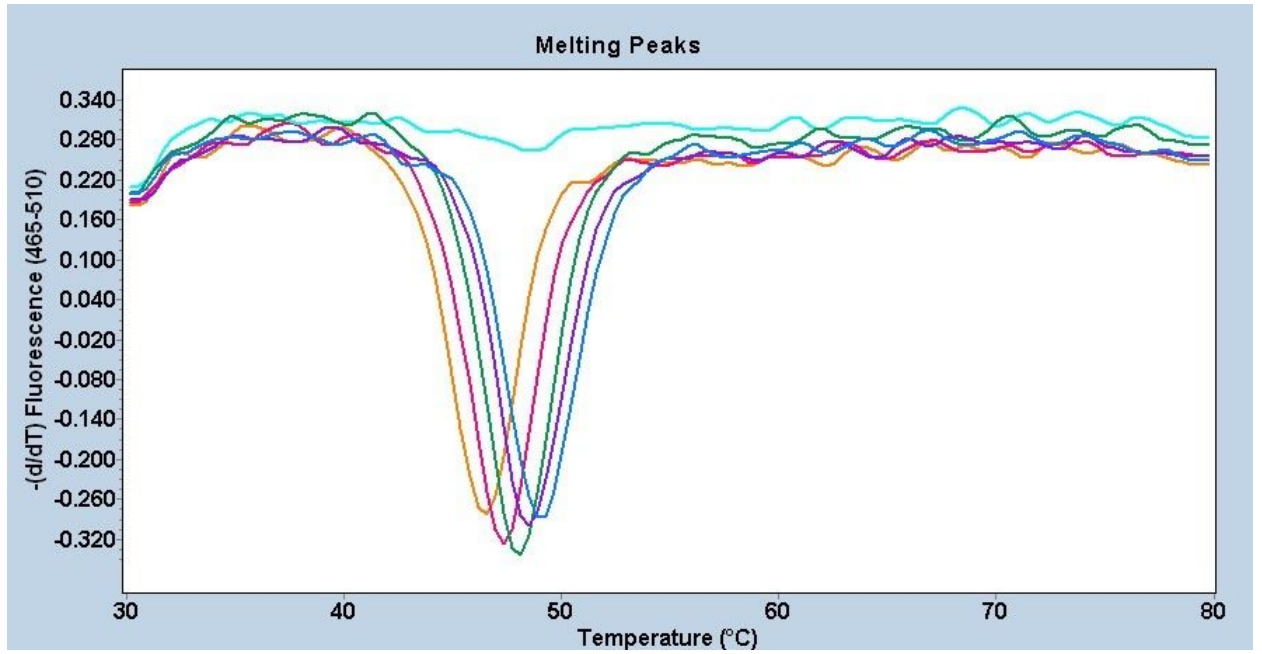

Figure S3. The influence of $\mathrm{Mg}^{2+}$ on the melting temperature. We designed 5 reaction systems, which differed in their $\mathrm{Mg}^{2+}$ concentrations $(0.5,1,2,2.5$ and $3 \mathrm{mM})$. We used the same HPV 18 plasmid sample, whose tag had a $\mathrm{Tm}$ of approximately $45^{\circ} \mathrm{C}$, to explore the changes in the $\mathrm{Tm}$. The original aim of this test was to identify the optimal $\mathrm{Mg}^{2+}$ concentration. From left to right, the 5 melting curves correspond to the reaction systems with 0.5 (orange line), 1 (fuchsia line), 2 (green line), 2.5 (purple line) and 3 (blue line) $\mathrm{mM} \mathrm{Mg}^{2+}$. We could clearly observe that the $\mathrm{Tm}$ of the sample increased as the $\mathrm{Mg}^{2+}$ concentration increased. 


\section{A}

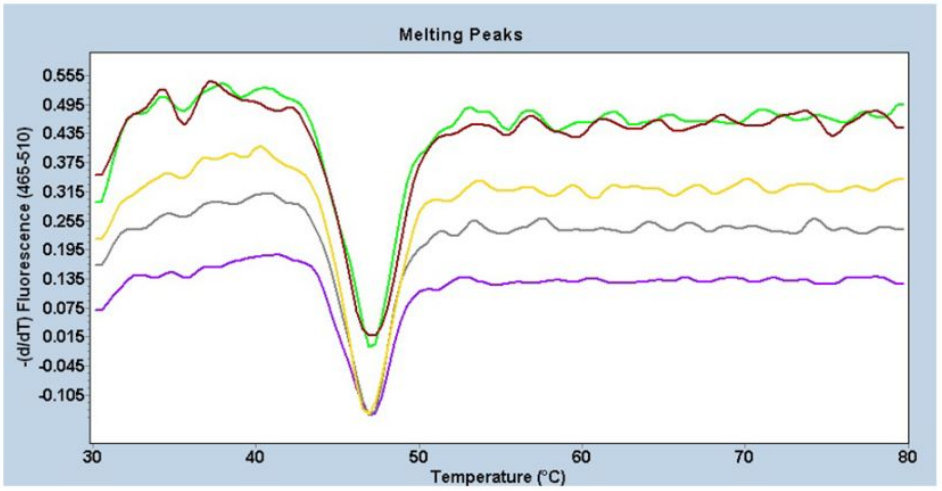

B

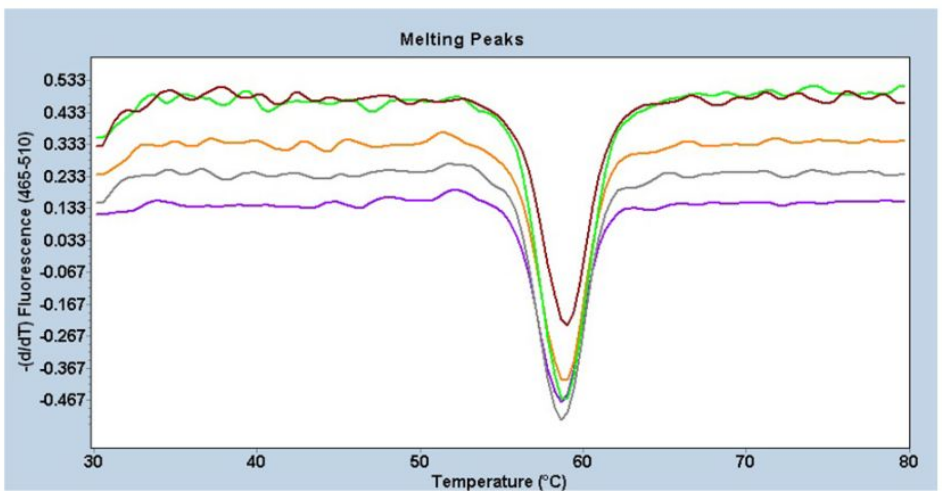

C

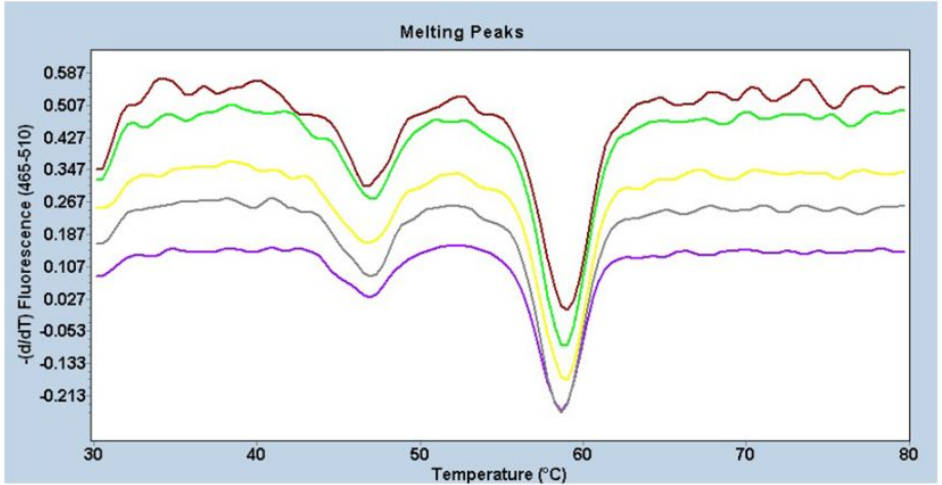

Figure S4. Optimal concentration of the probe exploring experiment. We used three samples and five 2D PCR systems to investigate the most suitable probe concentration. The melting curves of the different reaction systems are annotated in the figure. In all 3 curves, the purple, gray, yellow, green and brown lines correspond to the $25 \mu \mathrm{L} \mu \mathrm{L}$ reaction system with $0.1 \mu \mathrm{L}, 0.2 \mu \mathrm{L}, 0.3 \mu \mathrm{L}, 0.4 \mu \mathrm{L}$ and $0.5 \mu \mathrm{L}$ of the probes, respectively. From the three figures, we found that the best of the 5 reaction systems was the $25 \mu \mathrm{L}$ reaction system with $0.4 \mu \mathrm{L}$ of the probes (green melting curves). (A) The summary melting curves of the 5 reaction systems using plasmids with HPV 18 DNA. (B) The summary melting curves of the 5 reaction systems using human DNA samples extracted from whole blood. (C) The summary melting curves of the 5 reaction systems using the isotropic mix of plasmids with HPV 18 DNA and human DNA samples extracted from whole blood. 

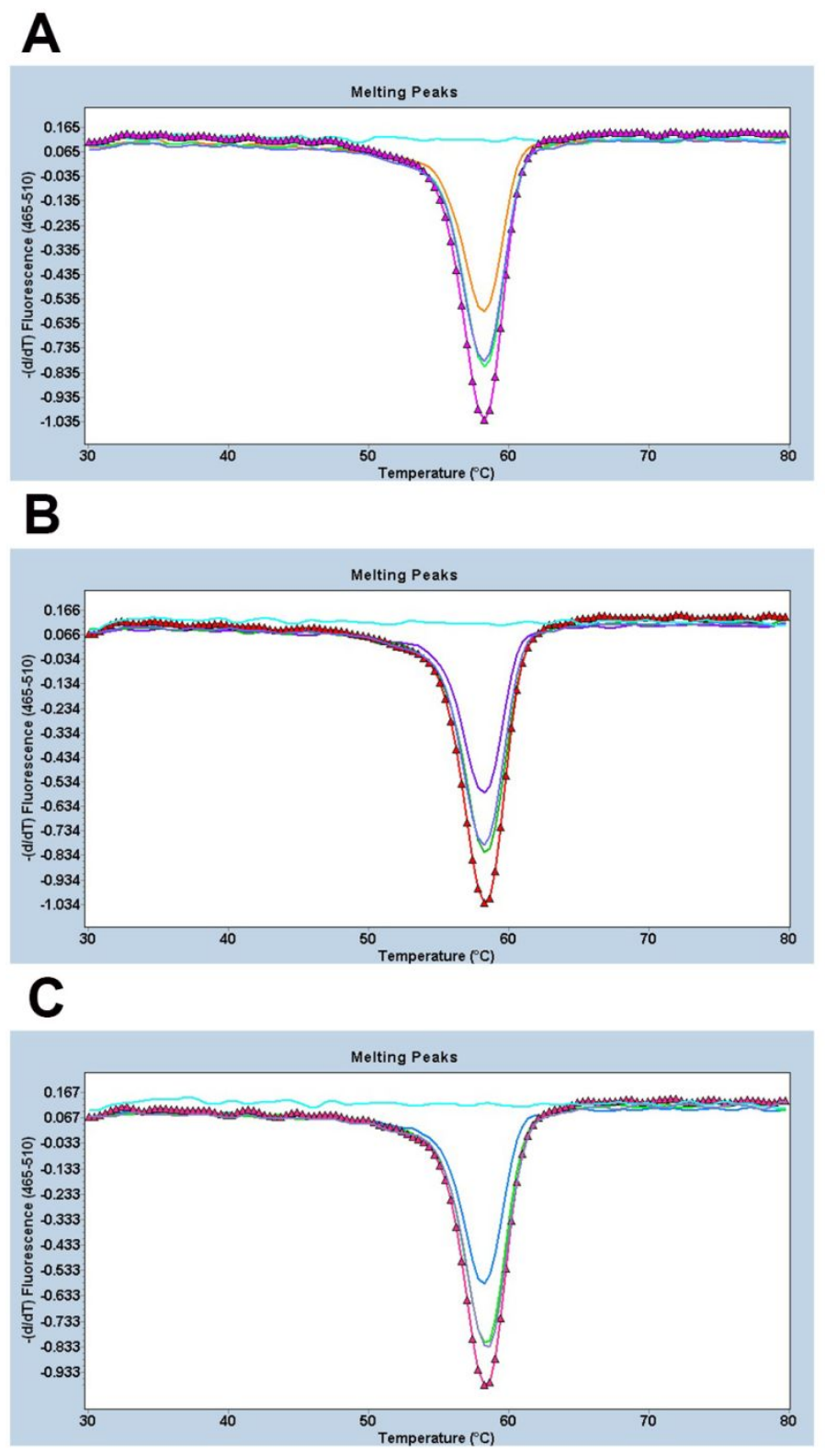

Figure S5. Untagged primer optimal concentration exploration. We diluted the human DNA samples ten-times to obtain three different concentrations: the lowest, medium and highest concentrations. The deepest melting valleys are marked with triangles. (A) The melting curves of the highest concentration of genomic DNA tested in the 4 reaction systems, where the line with the triangles corresponds to the reaction system with $0.6 \mu \mathrm{L}$ of the untagged primers. The orange, blue and green lines correspond to the $25 \mu \mathrm{L}$ reaction system with $0.2 \mu \mathrm{L}, 0.4 \mu \mathrm{L}$ and $0.8 \mu \mathrm{L}$ of the untagged primers, respectively. (B) The melting curves of the medium concentration genomic DNA sample tested in the 4 reaction systems; the line with triangles corresponds to the reaction system with $0.6 \mu \mathrm{L}$ of the untagged primers. The purple, blue and green lines correspond to the $25 \mu \mathrm{L}$ reaction system with $0.2 \mu \mathrm{L}, 0.4 \mu \mathrm{L}$ and $0.8 \mu \mathrm{L}$ of the untagged primers. (C) The melting curves of the lowest concentration genomic DNA samples tested in the 4 reaction systems, where the line with triangles corresponds to the reaction system with $0.6 \mu \mathrm{L}$ of the untagged primers. The blue, green and gray lines correspond to the $25 \mu \mathrm{L}$ reaction system with $0.2 \mu \mathrm{L}, 0.4 \mu \mathrm{L}$ and $0.8 \mu \mathrm{L}$ of the untagged primers. 


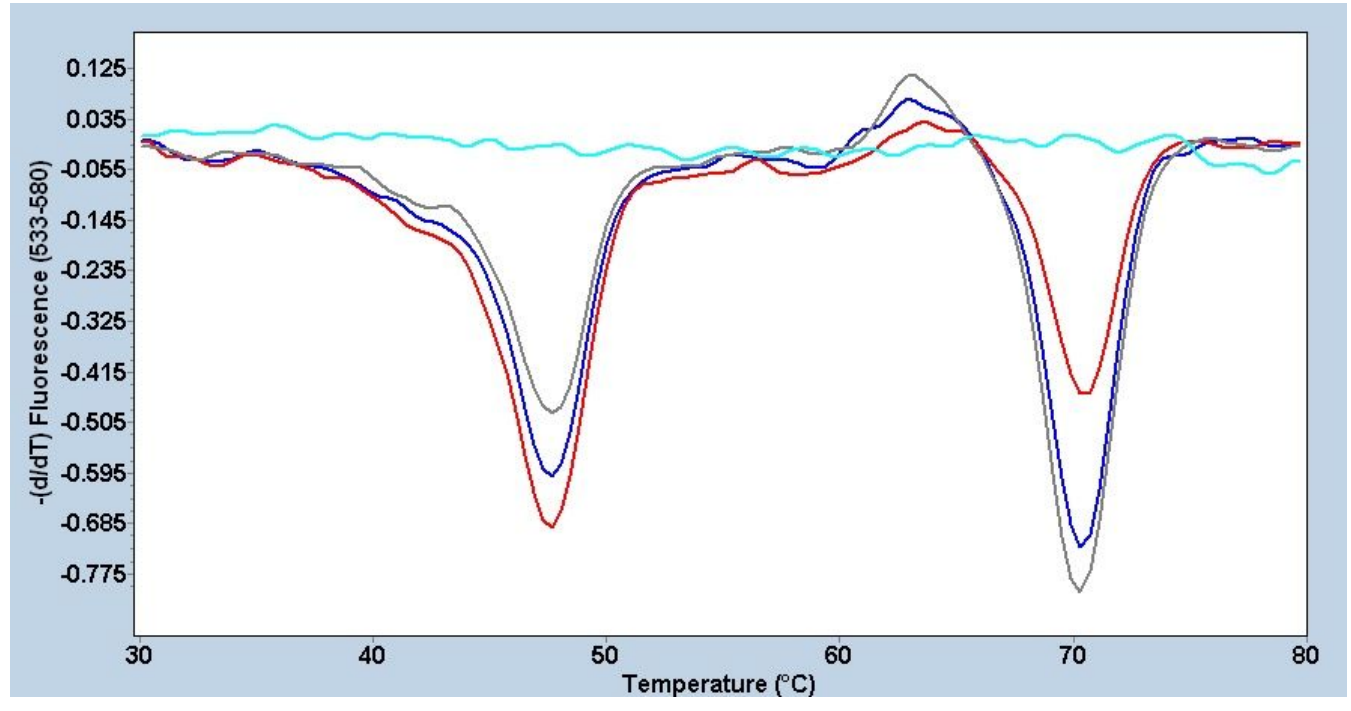

Figure S6. Change in the melting curve of the same HPV 45 sample with an increase in the HPV 68 plasmid concentration. The light blue line is the negative control. The gray melting curve is the $1 \times 10^{6}$ copies/ $\mu$ L HPV 45 plasmid with $1 \times 10^{7}$ copies/ $\mu$ L HPV 68 plasmid samples. The blue melting curve is $1 \times 10^{6}$ copies/ $\mu \mathrm{L}$ HPV 45 plasmid with $1 \times 10^{6}$ copies/ $\mu \mathrm{L}$ HPV 68 plasmid samples. The red melting curve is $1 \times 10^{6}$ copies/ $\mu \mathrm{L}$ HPV 45 plasmids with $1 \times 10^{5}$ copies/ $\mu \mathrm{L}$ HPV 68 plasmid samples. 